\title{
Accuracy of real-time shear wave elastography in staging hepatic fibrosis: a meta-analysis
}

\author{
Juan Fu', Biao Wu', Huazhi Wu', Feng Lin ${ }^{1}$ and Wei Deng ${ }^{2^{*}}$ (D)
}

\begin{abstract}
Background: Chronic liver disease (CLD) is an important cause of morbidity and mortality and can lead to hepatic fibrosis. This study was conducted to evaluate the diagnostic value of real-time shear wave elastography (SWE) in the assessment of hepatic fibrosis.

Methods: A systematic search of databases was performed for publications on SWE during the period between 2010 and 2017. The identified studies were analyzed using Meta-disc 1.4 software to integrate and analyze the data.

Results: Eleven studies comprising 1560 patients were included for analysis. The pooled sensitivity, specificity and diagnostic odds ratio were 0.85 ( $95 \% \mathrm{Cl}: 0.82-0.87), 0.79$ (95\% Cl: 0.76-0.82) and 30.81 (95\% Cl: 16.55-57.34), respectively for patients with a Metavir-score of $\geq$ F2; 0.87 (95\% Cl: 0.84-0.91), 0.84 (95\% Cl: 0.82-0.87), 41.45 (95\% Cl:18.25-94.45), respectively for patients with $\geq$ F3; 0.88(95\% Cl: 0.83-0.91), 0.91 (95\% Cl: 0.89-0.92), 67.18 (95\% Cl:30.02-150.31), respectively for patients with $\geq$ F4. The areas under the receiver operating characteristic curve of the three groups were $0.9147,0.9223$ and 0.9520 , respectively.
\end{abstract}

Conclusions: Our work demonstrates that SWE is highly accurate for detecting and staging hepatic fibrosis.

Keywords: Cirrhosis, Hepatic fibrosis, Elastography, Meta-analysis

\section{Background}

Chronic liver disease (CLD) is an important cause of morbidity and mortality and can lead to hepatic fibrosis, cirrhosis, portal hypertension, and hepatocellular carcinoma. CLD is a major health burden in the United States and around the world. During the course of CLD, the death and inflammation of hepatocytes can lead to excessive deposition of extracellular matrix and abnormal distribution, resulting in hepatic fibrosis and its complications. If not treated timely, this would eventually develop into cirrhosis [1]. The causes of this condition include the infection with hepatitis viruses, compromised autoimmune response, poisoning and metabolic damage. Effective treatment methods for CLD are now available and can prevent progression of the hepatic fibrotic process or even result in regression of fibrosis when administered in the early stages of fibrosis [2]. Currently, percutaneous liver biopsy

\footnotetext{
* Correspondence: dengweisums2@126.com

${ }^{2}$ Department of Oral and Maxillofacial Surgery, Hainan General Hospital, 19

Xiuhua Road, Haikou 570311, China

Full list of author information is available at the end of the article
}

is the standard of reference for clinical assessment of hepatic fibrosis [3, 4]. However, it is invasive and may cause complications because of puncture, although the assessment is accurate [5]. A reliable noninvasive technique is needed for detecting and staging fibrosis as well for as evaluating treatment response [6]. In the recent years, several quantitative and noninvasive techniques have become available for measurements of liver stiffness, such as realtime tissue elastography (RTE), transient elastography (TE) (Fibroscan; Echosense, Paris, France), and real-time shear wave elastography (SWE) (Aixplorer, Supersonic Imagine, France) [7, 8]. Among them, SWE is a relatively new imaging technique that allows an estimation of the stiffness of the tissues in a quantitative way $[9,10]$. It is based on the assumption that tissues that have pathological changes tend to be harder and less elastic than the surrounding healthy tissues. Estimation of the stiffness is based on the fact that the propagation of mechanical waves is greater in less elastic materials. The very quick data acquisition enables the assessment of tissue elasticity in real time as a colour map of stiffness superimposed

(c) The Author(s). 2020 Open Access This article is distributed under the terms of the Creative Commons Attribution 4.0 International License (http://creativecommons.org/licenses/by/4.0/), which permits unrestricted use, distribution, and 
over a grey-scaled B-mode. Putting a region of interest (ROI) in the area being investigated provides quantitative information about tissue elasticity in kilopascals or meter per second [11]. At present, SWE technology has been widely and successfully used in diagnosis of various diseases such as diseases in gland, vessel wall and superficial organ $[12,13]$. It is also used to detection of portal hypertension in cirrhosis which can use to reflect the liver stiffness with comparable or better success rate and accuracy as compared with TE [14] and can be used to diagnose patients with or without clinical significant portal hypertension [15].

Although many studies, including meta-analysis [16], have shown that liver elasticity measured by SWE is related to the pathological stage of fibrosis, the accuracy and diagnostic thresholds based on SWE are still controversial and the quality criteria and optimal number of measurements need to be defined [17]. Therefore, we performed a meta-analysis to assess the overall performance of SWE in the diagnosis of liver fibrosis.

\section{Methods}

This study was performed according to the Preferred Reporting Items for Systematic Reviews and MetaAnalyses statement [18]. Because this meta-analysis did not involve identifiable patient information, investigational review board approval was not necessary.

\section{Literature search}

A systematic search of PubMed (MEDLINE), Embase, Scopus, the Cochrane Library, the Web of Science, $\mathrm{Cu}-$ mulative Index to Nursing and Allied Health Literature, Google Scholar, China knowledge Network (http://www. cnki.net/), China Biology Medicine disc (http://www. sinomed.ac.cn/zh/), VIP (http://qikan.cqvip.com) and Wanfangd (http://www.wanfangdata.com.cn) databases was performed for the 7-year period prior to May 2017. An initial search strategy involving the following free text words "hepatic fibrosis," "elastography," "liver cirrhosis," "elasticity imaging techniques", "fibroscan", "liver physiology," "liver stiffness," "liver elasticity," "elasticity imaging techniques/methods," "ultrasonic elasticity imaging", "sensitivity and specificity," "reproducibility," "repeatability," and "reliability." In addition, a manual search of reference lists from primary studies was performed to locate any potential studies missed with electronic search strategies. The identified studies were then screened independently by two observers to identify studies that enable analysis of diagnostic odds ratio.

\section{Inclusion and exclusion criteria}

Inclusion criteria were as follows: (a) studies those study subjects were patients with liver fibrosis caused by various causes; (b) studies that used SWE to detect and stage the severity of fibrosis; (c) studies that clearly staged liver fibrosis based on the Metavir-score [19]. If 2 or more publications came from the same study, the publications with larger sample size were included. The exclusion criteria were as follows: (a) duplicate publication (based on the same primary study), (b) non-original research (such as reviews) and (c) studies with less than 30 patients. The final list of studies that met the inclusion and exclusion criteria were reviewed by all authors.

\section{Data extraction and quality verification}

The data were extracted by using a predefined form. The following data were extracted: (a) author, journal, and year of publication; (b) number of subjects; (c) cause of disease; $(d)$ average age and gender; $(e)$ data related to disease staging by SWE and liver biopsy and $(f)$ data to calculate the number of true positive, false positive, true negative and false negative. Data quality was assessed by using the Quality Assessment of Studies of Diagnostic Accuracy (QUADAS)-2 tool [20]. Disagreements were resolved by discussion between the investigators.

\section{Statistical analysis}

Meta-DiSc 1.4 (http://www.hrc.es/investigacion/metadisc_en. $\mathrm{htm}$ ), a software for meta-analysis of test accuracy was used to calculate the sensitivity, specificity, diagnostic odds ratio (DOR) and the 95\% confidence interval (95\% CI) and to analyze summary receiver operating characteristic curves (SROC) and the area under curve (AUC) [21, 22]. Forrest plots of sensitivities and specificities were constructed of the accuracy of SWE assessment of fibrosis. ROC plots of DOR was performed to determine threshold effect. $\chi 2$-test and Cochrane- $\mathrm{Q}$ were used to determine the heterogeneity of DOR. If inconsistency $\left(\mathrm{I}^{2}\right) \geq 25 \%$, and $P<0.05$, DOR was considered heterogeneous, and random effect mode was chosen. Otherwise, fixed effect mode was chosen.

\section{Results \\ Study search}

Two hundred and fifty-five Chinese paper and 388 English paper were revealed in the preliminary search. Duplicate articles were removed, and a list of 528 articles was collected in a single electronic library. After a detailed manual review, 11 articles met the inclusion and exclusion criteria. A flow diagram according to PRISMA guidelines of studies included is shown in Fig. 1. All studies included in the meta-analysis fulfilled four or more of the seven categories of the QUADAS-2 tool [20]. Baseline characteristics of included studies are shown in Table 1. The 11 articles which reported SWE-based fibrosis assessment were included for meta-analysis, were conducted in the United States, Italy, China, Korea, Japan, France, Romania and Turkey. There were 1560 patients aged between 12 to 82 years. The etiology of diseases was categorized as hepatitis $\mathrm{C}$ virus (HCV), hepatitis B virus (HBV), and others. 


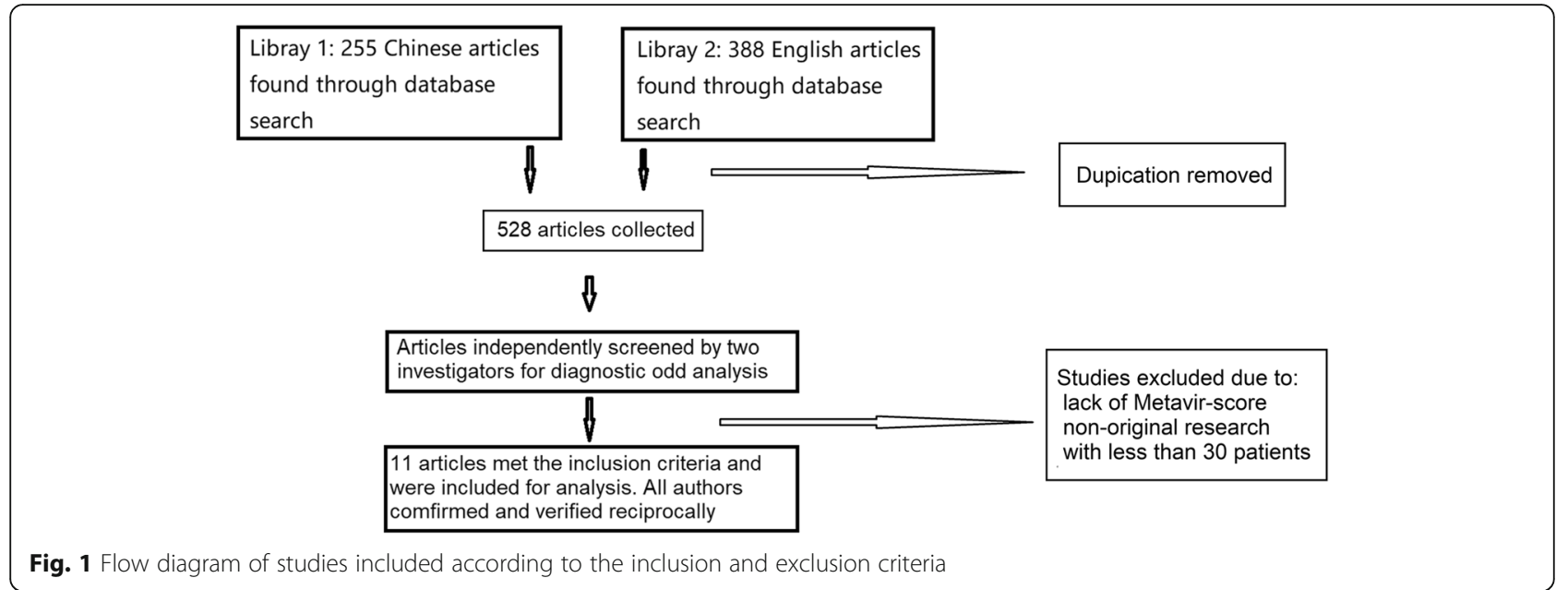

The METAVIR scoring system was used to classify the disease severity, which was between F2 and F4. Among the studies, 11, 8 and 9 reported diagnostic value of SWE in patients with $\geq F 2$, $\geq F 3$ and $\geq F 4$, respectively. It should be mentioned that in the study conducted by Beland et al., the liver stiffness was measured in $\mathrm{kPa}$ on an ultrasound machine and converted to $\mathrm{m} / \mathrm{s}$ by using a conversion formula [32] . The cut-off values of various etiologies are summarized in Table 2. Chronic viral liver diseases appeared to have lower cutoff values as compared with non-viral liver diseases such as non-alcoholic fatty liver disease, while autoimmune liver disease had high cut-off value (Table 2).

\section{Meta-analysis}

Due to insufficient number of study (four out of 11 included studies) and number of patients (56 patients), studies that reported patients at the hepatic fibrosis stage of F0 to F1 were considered inappropriate for meta-analysis. $\mathrm{I}^{2}$ in $\geq \mathrm{F} 2, \geq \mathrm{F} 3$ and $\geq$ F4 groups were $73.0,76.4$ and $65.1 \%$ (Fig. 2), respectively, indicating that there were non-threshold effects in all three groups and could be analyzed by as random effect mode. The combined DOR of $\geq F 2, \geq F 3$ and $\geq F 3$ were 30.81 (95\% CI: 16.55-57.34); 41.45 (95\% CI: 18.25-94.45); and 67.18 (95\% CI: 30.03-150.31) (Fig. 2). The sensitivity and specificity of DOR of $\geq F 2, \geq F 3$ and $\geq$ F3 groups were 0.85 (95\% CI: $0.82-0.87$ ) and 0.79 (95\% CI: $0.76-0.82$ ); 0.87 (95\% CI: $0.84-0.91$ ) and 0.84 (95\% CI: $0.82-0.87$ ); and 0.88 (95\% CI: 0.83-0.91) and 0.91 (95\% CI: 0.89-0.92), respectively. The AUC of DOR were $0.920,0.922$ and 0.952 in $\geq F 2$, $\geq$ F3 and $\geq$ F4 group, respectively (Fig. 3).

\section{Discussion}

Our study shows SWE has high sensitivity and specificity to detecting and staging hepatic fibrosis in patients with $\geq$ F2 Metavir-score. The AUC of DOR in these patients are all over 0.92, suggesting that it has higher diagnostic values. There are several advantages of this method. Studies showed that it has excellent intraobserver and interobserver error, intraclass correlation coeffiients in three different sections of the liver ranged from 0.86 to 0.98 , and the $95 \%$ confidence interval ranged from 0.71 to 0.99 , suggesting the technique is highly reproducible $[23,26]$.

Table 1 Characteristics of studies assessing the performance of SWE for staging of liver fibrosis

\begin{tabular}{lllllll}
\hline Studies included & Year & Country & Averaged age (range) & Sample size & Etiology & Liver fibrosis stage \\
\hline Ferraioli et al. [23] & 2012 & Italy & $44.8(19-76)$ & 121 & Chronic hepatitis C & F2, F3, F4 \\
Jeong et al. [10] & 2014 & Korea & $45.9(12.0-82.0)$ & 70 & Chronic liver disease & F2, F3, F4 \\
Samir et al. [9] & 2015 & US & $47.0(18-74)$ & 136 & Chronic liver disease & F2, F3, F4 \\
Tutar et al. [24] & 2014 & Turkey & $7.7(0.3-17)$ & 76 & Chronic liver disease & F2 \\
Tada et al. [25] & 2015 & Japan & 61.0 & 55 & Chronic hepatitis C & F2 \\
Leung et al. [26] & 2013 & Korea & 48.8 & 226 & Chronic hepatitis B & F1, F2, F3, F4 \\
Sporea et al. [27] & 2014 & Romania & $52.0(18-82)$ & 250 & Chronic liver disease & F1, F2, F3, F4 \\
Guibal et al. [28] & 2015 & France & 54.3 & 148 & Chronic liver disease & F2, F3, F4 \\
Zheng et al. [29] & 2015 & China & $37.7(18-67)$ & 167 & Chronic liver disease & F2, F4 \\
Yegin et al. [30] & 2015 & Turkey & $45.3(17-75)$ & 105 & Chronic liver disease & F1, F2, F3, F4 \\
Zeng et al. [31] & 2014 & China & $36.3(20-59)$ & 206 & Chronic hepatitis C & F2, F3, F4 \\
\hline
\end{tabular}


Table 2 The diagnostic threshold (kPa) of 2D-SWE in staging of liver fibrosis in patients with chronic liver disease

\begin{tabular}{lllll}
\hline Etiology & FF2 & ZF3 & F4 & Studies \\
\hline Chronic hepatitis C & 7.1 & 8.7 & 10.4 & Ferraioli et al. [23] \\
Chronic hepatitis C & 7.3 & 8.9 & 9.6 & Samir et al. [9] \\
Chronic hepatitis B & 7.1 & 7.9 & 10.1 & Leung et al. [26] \\
Chronic hepatitis B & 7.2 & 9.1 & 11.7 & Zeng et al. [31] \\
Chronic hepatitis B & 8.8 & 11.5 & 18.1 & Guibal et al. [28] \\
Nonalcoholic fatty liver disease & 8.7 & 10.7 & 14.4 & Cassinotto et al. [24] \\
Autoimmune liver disease & 9.7 & 13.2 & 16.3 & Zhang et al. [29] \\
Various chronic liver diseases & 8.6 & 10.5 & 14.0 & Jeong et al. [10] \\
\hline
\end{tabular}

An non-invasive procedure, it is very suitable for detecting therapeutic outcome after operations, such as liver transplantation [33] and can be used for screening and subsequent management of liver diseases, particularly for children [34]. Other advantages of this method include determining therapeutic response, and monitoring age-related changes, including sarcopenia and clinical frailty syndrome. For example, the therapeutic outcome of Entecavir for chronic hepatitis B may be assessed using 2D-SWE to determine the change in stiffness of liver over a long term period to better treatment management and prognosis [35]. By quantifying mechanical and elastic tissue properties, SWE complements the diagnosis obtained at gray-scale (Bmode) US and power and color Doppler US [36].

The studies included in this analysis has high heterogeneity due to non-threshold effect. The main causes of heterogeneity were the etiology of liver fibrosis in the patients, which might result from infection of various hepatitis virus and fatty liver. Previous studies have shown that different causes of liver fibrosis may lead to different elastic threshold value for F2 or cirrhosis in TE-based assessment of fibrosis [37]. For liver fibrosis in chronic hepatitis C, the liver stiffness values were found to increase in parallel with degree of liver fibrosis when assessed with SWE and SWE was more accurate than TE in assessing significant fibrosis ( $\geq$ F2) [23]. SWE has the advantage of imaging liver stiffness in real time while guided by a B-mode image. Thus, the region of measurement can be guided with both anatomical and tissue stiffness information.

In this study, we analyzed 11 studies that met with inclusion criteria and found that the AUC was over 90\% for fibrosis at F2, F3 and F4 stages, indicating that SWE is accurate to assess fibrosis at different stage.

The earliest technique FibroScan (FibroScan; Echosens, Paris, France) used in clinical assessment of liver elastic modulus is TE developed by Echosen. It is based on the measurement of the propagation velocity of shear waves in liver tissue and is noninvasive, quantitative and real-time technique to assess the degree of liver fibrosis. However, it is a one-dimensional imaging technology and needs special mechanical vibrating device to generate shear wave, and cannot be used for patients with ascites, obesity and stenosed rib space stenosis [38]. It cannot take two-dimensional images to avoid the nontarget structure in the liver [7,39]. SWE is a newer elastic imaging technology which is a newer variant of RTE [40]. Different from earlier technology, it uses shearwave and does not need to compress and decompress the tissues to generate strain [41]. The shear waves are generated using acoustic radiation force automatically induced by the supersonic speed. This technique allows the measurement of the propagation speed of shear waves within tissues in meters per second $(\mathrm{m} / \mathrm{s})$ to locally quantify tissue stiffness (Young's modulus) in kilopascals $(\mathrm{KPa})$ and is less operator-dependent $[42,43]$. 2D SWE is based on ultra-fast ultrasound tracking technology and Young's modulus formula to display elastic images in real time and show the stiffness of the tissue with different color. It can avoid the inference from the structure of intrahepatic ducts to quantitatively assess the elastic modulus of liver tissue to quantify the stiffness of liver tissue hardness value, thus effectively increasing the accuracy of assessment and having broad clinical applications $[44,45]$. On other side, RTE, also a noninvasive diagnostic technique that examines the stiffness and hardness of tissue, is mainly used to assess superficial tissues, such as neck, prostate, breast, and thyroid, by testing the elasticity $[46,47]$.

Our analysis showed that the pooled sensitivity (88\%) and specificity (91\%) of SWE in detecting and staging early cirrhosis (F1) are similar to those of TE [37, 48], acoustic radiation force impulse (ARFI) [49] and RTE $[50,51]$, those sensitivity and specificity are 83 and $89 \%$, 87 and $87 \%, 74$ and $84 \%$, respectively. ARFI is very similar to SWE, which targets an anatomic region to be interrogated for elastic properties with a Region-ofInterest (ROI) cursor [52]. However, for significant fibrosis $(F \geq 2)$, the overall sensitivity and specificity of SWE are greater than these of TE and RTE, and similar to these of ARF. For TE and RTE, the combined sensitivity is $79 \%$ and the combined specificity is 78 and $76 \%$, respectively; while for ARFI [49], the combined sensitivity and specificity are 74 and $83 \%$. Clinically, the differentiation of nonadvanced (F0 and F1) and advanced (F2-F4) fibrosis is particularly relevant in $\mathrm{HCV}$ hepatitis $\mathrm{C}$ virus, where advanced fibrosis at the time of diagnosis has been shown to correlate with long-term cirrhosis risk, because once diagnosed as significant hepatic fibrosis $(\mathrm{F} \geq 2)$, these patients have high risks to develop cirrhosis [53-55]. In this aspect, SWE may fill an important gap [56]. In addition, ultrasonic elasticity technologies, such as ARFI and TE, have some limitations and their measurements are affected by tissue inflammation and steatosis, which do not affect the SWE assessment of liver 
A

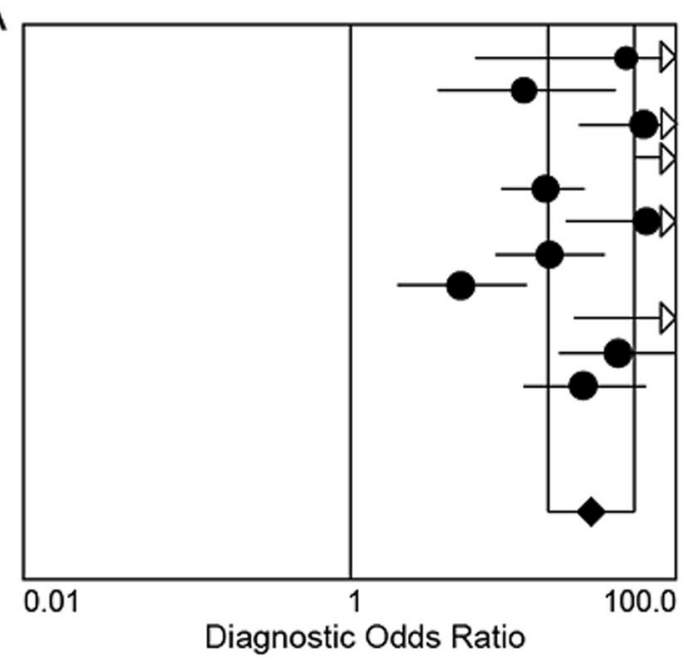

B

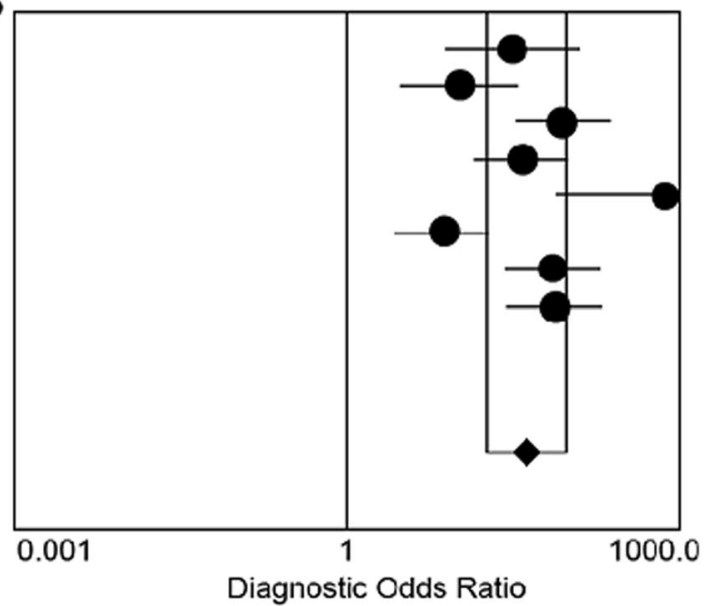

C

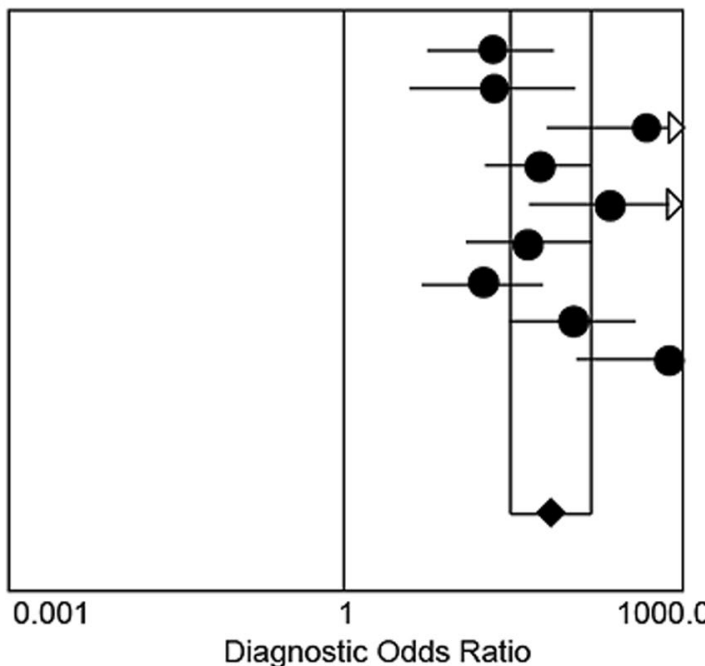

Diagnostic OR $(95 \% \mathrm{Cl})$

Jeong et al Samir et al Leung et al

Tutar et al

Sporea et al

Ferraioli et al

Zheng et al

Yegin et al

Tada et al

Zeng et al

Guibal et al

50.17 (5.98-421.00)

$11.78(3.39-40.95)$

$64.93(26.38-159.83)$

$645.00(55.92-7439.62)$

$15.67(8.41-29.17)$

$67.05(21.10-213.03)$

$17.00(7.79-37.10)$

$4.66(1.84-11.79)$

$288.00(24.32-3410.47)$

$44.19(19.58-99.47)$

$27.28(11.26-66.10)$

Random Effects Model

Pooled Diagnostic Odds Ratio $=30.81(16.55$ to 57.34$)$

Cochran - $\mathrm{Q}=37.06$; df $=10(P=0.0001)$

Inconsistency $(1-$ square $)=73.0 \%$

Tau-square $=0.7163$

Jeong et al

Samir et al

Leung et al

Sporea et al

Ferraioli et al

Yegin et al

Zeng et al

Guibal et al

Diagnostic OR $(95 \% \mathrm{Cl})$

$$
\begin{aligned}
& 31.00(8.19-117.27) \\
& 10.56(3.19-35.00) \\
& 84.86(33.99-211.85) \\
& 36.60(13.83-96.86) \\
& 730.75(78.91-6767.57) \\
& 7.36(2.98-18.22) \\
& 71.98(25.75-201.24) \\
& 74.40(23.90-231.63)
\end{aligned}
$$

Random Effects Model

Pooled Diagnostic Odds Ratio $=41.51$ (18.25 to 94.42)

Cochran $-\mathrm{Q}=29.62 ; \mathrm{df}=7(P=0.0001)$

Inconsistency $(1-$ square $)=76.4 \%$

Tau - square $=1.0335$

Jeong et al

Diagnostic OR $(95 \% \mathrm{Cl})$

Samir et al

$19.91(5.54-71.58)$

Leung et al

Sporea et al

$20.38(3.58-115.91)$

465.54 (58.93-3 677.42)

$52.86(18.95-147.50)$

Ferraioli et al

$219.33(41.34-1163.70)$

Zheng et al

Yegin et al

$40.57(11.53-142.75)$

$16.20(5.04-52.10)$

$105.88(29.43-380.88)$

Guibal et al

$812.00(109.57-6017.62)$

Random Effects Model

Pooled Diagnostic Odds Ratio $=67.18$ (30.03 to 150.31)

Cochran $-\mathrm{Q}=22.93 ; \mathrm{df}=8(P=0.0035)$

Inconsistency $(1-$ square $)=65.1 \%$

Tau - square $=0.9516$

Fig. 2 Forest plots of diagnostic odds ratios (DOR) from 11 test accuracy studies showing the results from 11 studies in detecting and staging hapetic fibrosis. $\mathbf{a} \geq F 2, \mathbf{b} \geq F 3$, and $\mathbf{c} \geq F 4$ 


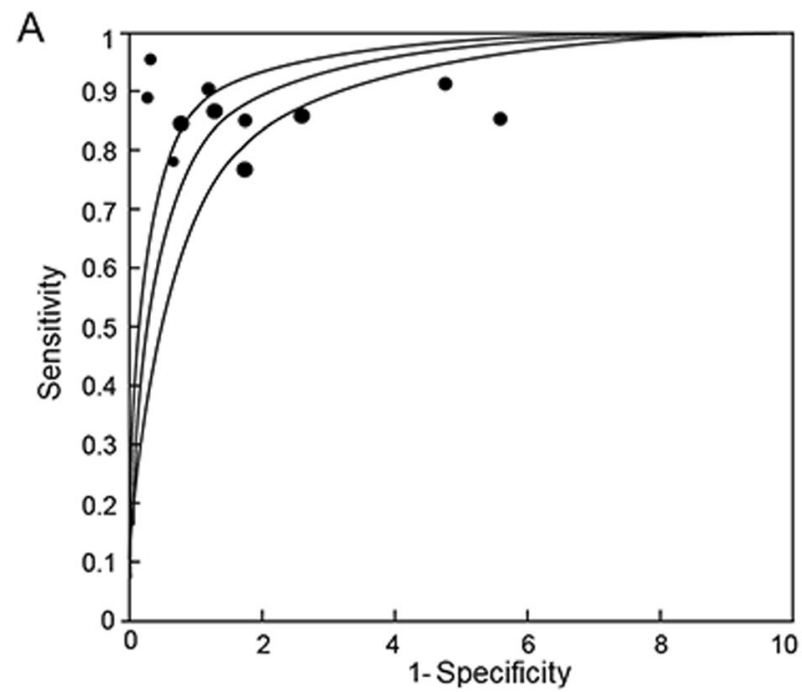

Symmetric SROC

AUC $=0.9204$
$S E(A \cup C)=0.0131$

$\mathrm{SE}(A \cup C)=0.0131$

SE $\left(Q^{*}\right)=0.0151$

B

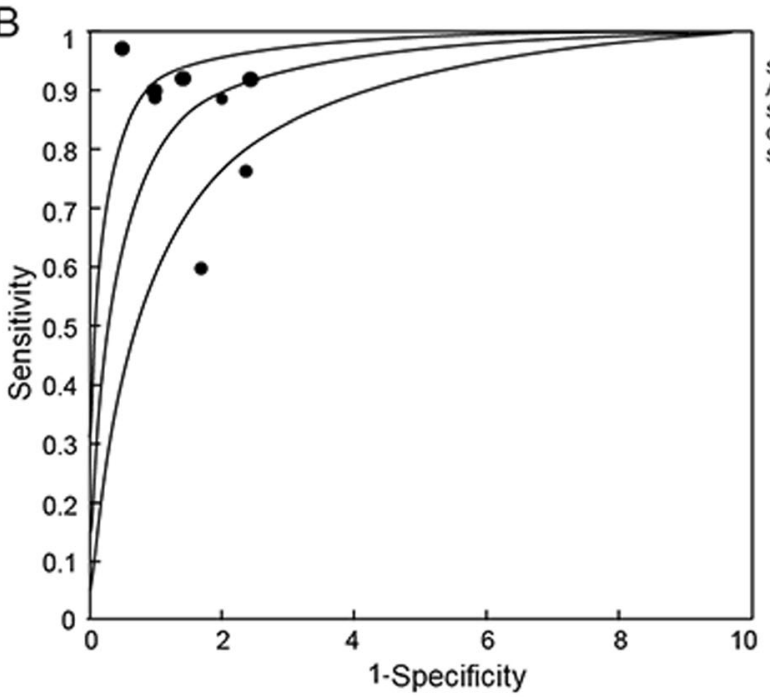

Symmetric SROC

$\mathrm{AUC}=0.9223$

SE (AUC) $=0.0219$

$0^{*}=0.8560$

$\operatorname{SE}\left(Q^{*}\right)=0.0254$

C

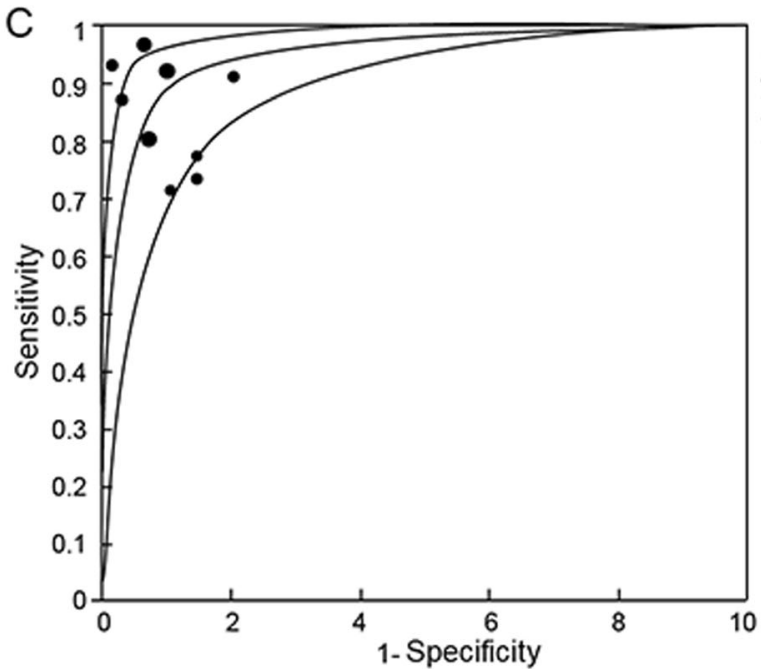

Symmetric SROC

AUC $=0.9529$

SE $(A \cup C)=0.0184$

$Q^{*}=0.8932$

$\operatorname{SE}\left(Q^{*}\right)=0.0252$

Fig. 3 Summary receiver operating characteristic (SROC) curves with 95\% confidenceintervals (shown as upper and lower curves) for estimating the diagnosis accuracy of SWE $\mathbf{a} \geq F 2, \mathbf{b} \geq F 3$, and $\mathbf{c} \geq$ F4. Dots represent the sensitivity and specificity of each included study 
fibrosis [9]. For example, TE is adequate for a diagnosis of cirrhosis, but its accuracy for milder stages of fibrosis is much less satisfactory. ARFI was not associated with alanine aminotransferase (ALT), body mass index, Metavir grade, and liver steatosis. On other hand, TE was significantly correlated with the ALT value [57], but the accuracy of ARFI was influenced by sex, interquartile range interval, high alanine aminotransferases and high aspartate aminotransferases levels [58].

There are a number of factors that would affect the evaluation performance for the liver stiffness by SWE, such as the number of measurements, liver volumes, patient's conditions such as overweight or obesity or other complications as well as the fibrosis stage and experience of operators [25, 27]. It is generally agreed that three measurements are sufficient to obtain consistent results for assessing liver fibrosis [11]. However, more measurements help reducing unreliable measurements [10]. The fibrosis stage, GGT and serum albumin are shown to significantly influence the stiffness measurement [31], although use of different equipment and working methodologies in different studies make it difficult to compare these influences [30]. The causes of chronic liver disease are also important factor that influence the liver stiffness. For example, the cutoff points for $\geq \mathrm{F} 1$ in patients with chronic nonviral hepatitis (alcoholic or nonalcoholic steatohepatitis) and chronic viral hepatitis (B) were $6.5 \mathrm{kPa}$ and $6.8 \mathrm{kPa}$, respectively [25, 27]. On other hand, as shown in Table 2, fibrosis etiologies such as $\mathrm{HCV}$ or HBV infections give similar SWE performances, while nonalcoholic fatty liver disease and autoimmune liver disease generate high liver stiffness. Although included studies did not report the influence of liver viscosity on the results of SWE, Deffieux et al. reported a correlated between viscosity and the degree of liver fibrosis, but not with steatosis or disease activity [59]. In addition, older age and higher BMI were associated with impossibility to obtain reliable measurements [25]. As such, quality criteria for $2 \mathrm{D}-\mathrm{SWE}$ is very important to obtain reliable measurement. For example, Yoon et al. used a value of less than 0.3 for standard deviation/mean 2D-SWE value to control the measurement quality [60]. Age appears an important factors affecting the measurement and children are found to have higher cutoff value for liver fibrosis [24]. This, however, may be due to the difference in the etiology of chronic liver disease between children and adult population.

The cutoff values for the diagnosis of fibrosis were reported in some of the included studies (Table 2). Although the values increase generally with increased fibrosis stage, they are slightly different among the studies even the etiology is the same. For example, Zeng et al. reported that cutoff ( $\mathrm{kPa}$ ) for F2. F3 and F4 fibrosis stage were 7.2, 9.1 and 11.7 for chronic hepatitis B- induced liver fibrosis [31], while Guibal et al. found that these values were 8.8, 11.5 and 18.1 [28]. For children, the cut-off value could be even higher $(10.6 \mathrm{kPa})$ [30]. It is likely that the machines and methodologies used in SWE would impact the cut-off value, as well as the site of measurement [9]. Therefore, it is important to develop institute-specific standard for SWE-based diagnosis for liver fibrosis.

Limitations of our study included inhomogeneity owing to causes of disease, small numbers of studies included. Studies with F0-F1 were not included due to insufficient data availability. In addition, not all subjects underwent biochemical hepatic tests and viral marker assessments for verification of etiology.

\section{Conclusion}

Our study has shown that SWE is accurate in diagnosing significant, advanced fibrosis and early cirrhosis of the liver. However, since liver fibrosis has various etiology which may generate different liver stiffness as discussed above, the diagnosis cutoff threshold need to be adjusted case by case based on other information, such as laboratory assessment of the cause of the disease. Due to the limited number of studies included in this study, there is a need to further investigate the relationship between tissue elasticity and liver fibrosis severity.

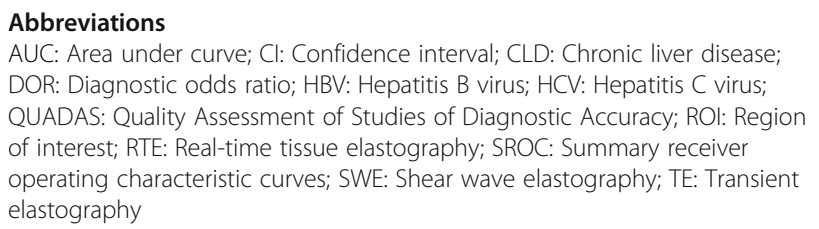

\section{Authors' contributions}

JF and WD designed the study. JF, BW and HW searched and reviewed the data. HW and FL performed analysis. JF, BW and WD drafted the manuscript. All authors read and approved the final manuscript.

\section{Funding}

This study was supported by The National Natural Science Foundation of China (grant no:81360172).

\section{Availability of data and materials}

The datasets used and/or analysed during the current study are available from the corresponding author on reasonable request.

Ethics approval and consent to participate

Because this meta-analysis did not involve identifiable patient information, investigational review board approval was not necessary.

\section{Consent for publication}

$\mathrm{N} / \mathrm{A}$.

Competing interests

The authors declare that they have no competing interests. 


\section{Author details}

'Department of Infectious Disease, Hainan General Hospital, Haikou, China. ${ }^{2}$ Department of Oral and Maxillofacial Surgery, Hainan General Hospital, 19 Xiuhua Road, Haikou 570311, China.

Received: 20 September 2019 Accepted: 20 January 2020

Published online: 11 February 2020

\section{References}

1. Zhou WC, Zhang QB, Qiao L. Pathogenesis of liver cirrhosis. World J Gastroenterol. 2014;20(23):7312-24

2. Pariente $D$, Franchi-Abella S. Paediatric chronic liver diseases: how to investigate and follow up? Role of imaging in the diagnosis of fibrosis. Pediatr Radiol. 2010;40(6):906-19.

3. Bravo AA, Sheth SG, Chopra S. Liver biopsy. N Engl J Med. 2001;344(7):495-500.

4. Ovchinsky N, Moreira RK, Lefkowitch JH, Lavine JE. Liver biopsy in modern clinical practice: a pediatric point-of-view. Adv Anat Pathol. 2012;19(4):250-62.

5. Takyar V, Etzion O, Heller T, Kleiner DE, Rotman Y, Ghany MG, Fryzek N, Williams VH, Rivera E, Auh S, et al. Complications of percutaneous liver biopsy with Klatskin needles: a 36-year single-Centre experience. Aliment Pharmacol Ther. 2017;45(5):744-53.

6. Towbin AJ, Serai SD, Podberesky DJ. Magnetic resonance imaging of the pediatric liver: imaging of steatosis, iron deposition, and fibrosis. Magn Reson Imaging Clin N Am. 2013;21(4):669-80.

7. Sigrist RMS, Liau J, Kaffas AE, Chammas MC, Willmann JK. Ultrasound Elastography: review of techniques and clinical applications. Theranostics. 2017;7(5):1303-29.

8. Song P, Zhao H, Manduca A, Urban MW, Greenleaf JF, Chen S. Comb-push ultrasound shear elastography (CUSE): a novel method for two-dimensional shear elasticity imaging of soft tissues. IEEE Trans Med Imaging. 2012;31(9):1821-32.

9. Samir AE, Dhyani M, Vij A, Bhan AK, Halpern EF, Mendez-Navarro J, Corey KE, Chung RT. Shear-wave elastography for the estimation of liver fibrosis in chronic liver disease: determining accuracy and ideal site for measurement. Radiology. 2015;274(3):888-96.

10. Jeong JY, Kim TY, Sohn JH, Kim Y, Jeong WK, Oh YH, Yoo KS. Real time shear wave elastography in chronic liver diseases: accuracy for predicting liver fibrosis, in comparison with serum markers. World J Gastroenterol. 2014;20(38):13920-9.

11. Dietrich CF, Bamber J, Berzigotti A, Bota S, Cantisani V, Castera L, Cosgrove D, Ferraioli G, Friedrich-Rust M, Gilja OH, et al. EFSUMB guidelines and recommendations on the clinical use of liver ultrasound Elastography, update 2017 (long version). Ultraschall Med. 2017;38(4):e48.

12. Tian J, Liu Q, Wang X, Xing P, Yang Z, Wu C. Application of 3D and 2D quantitative shear wave elastography (SWE) to differentiate between benign and malignant breast masses. Sci Rep. 2017;7:41216.

13. Taljanovic MS, Gimber LH, Becker GW, Latt LD, Klauser AS, Melville DM, Gao L, Witte RS. Shear-wave Elastography: basic physics and musculoskeletal applications. Radiographics. 2017;37(3):855-70.

14. Elkrief L, Rautou PE, Ronot M, Lambert S, Dioguardi Burgio M, Francoz C, Plessier A, Durand F, Valla D, Lebrec D, et al. Prospective comparison of spleen and liver stiffness by using shear-wave and transient elastography for detection of portal hypertension in cirrhosis. Radiology. 2015;275(2):589-98.

15. Jansen C, Bogs C, Verlinden W, Thiele M, Moller P, Gortzen J, Lehmann J, Vanwolleghem T, Vonghia L, Praktiknjo M, et al. Shear-wave elastography of the liver and spleen identifies clinically significant portal hypertension: a prospective multicentre study. Liver Int. 2017;37(3):396-405.

16. Li C, Zhang C, Li J, Huo H, Song D. Diagnostic accuracy of real-time shear wave Elastography for staging of liver fibrosis: a meta-analysis. Med Sci Monit. 2016;22:1349-59.

17. Kim DW, Suh CH, Kim KW, Pyo J, Park C, Jung SC. Technical performance of two-dimensional shear wave Elastography for measuring liver stiffness: a systematic review and meta-analysis. Korean J Radiol. 2019;20(6):880-93.

18. Moher D, Liberati A, Tetzlaff J, Altman DG, Group P. Preferred reporting items for systematic reviews and meta-analyses: the PRISMA statement. Int J Surg. 2010;8(5):336-41.

19. Bedossa P, Poynard T. An algorithm for the grading of activity in chronic hepatitis C. The METAVIR Cooperative Study Group. Hepatology. 1996;24(2):289-93.

20. Whiting P, Rutjes AW, Reitsma JB, Bossuyt PM, Kleijnen J. The development of QUADAS: a tool for the quality assessment of studies of diagnostic accuracy included in systematic reviews. BMC Med Res Methodol. 2003;3:25.
21. Zamora J, Abraira V, Muriel A, Khan K, Coomarasamy A. Meta-DiSc: a software for meta-analysis of test accuracy data. BMC Med Res Methodol. 2006;6:31.

22. Moses LE, Shapiro D, Littenberg B. Combining independent studies of a diagnostic test into a summary ROC curve: data-analytic approaches and some additional considerations. Stat Med. 1993;12(14):1293-316.

23. Ferraioli G, Tinelli C, Dal Bello B, Zicchetti M, Filice G, Filice C, Liver Fibrosis Study G. Accuracy of real-time shear wave elastography for assessing liver fibrosis in chronic hepatitis C: a pilot study. Hepatology. 2012;56(6):2125-33.

24. Tutar O, Beser OF, Adaletli I, Tunc N, Gulcu D, Kantarci F, Mihmanli I, Cokugras FC, Kutlu T, Ozbay G, et al. Shear wave elastography in the evaluation of liver fibrosis in children. J Pediatr Gastroenterol Nutr. 2014;58(6):750-5.

25. Tada T, Kumada T, Toyoda H, Ito T, Sone Y, Okuda S, Tsuji N, Imayoshi Y, Yasuda E. Utility of real-time shear wave elastography for assessing liver fibrosis in patients with chronic hepatitis $C$ infection without cirrhosis: comparison of liver fibrosis indices. Hepatol Res. 2015;45(10):E122-9.

26. Leung WY, Shen J, Wong WW, Abrigo J, Wong GL, Chim AM, Chu SH, Chan AW, Choi PC, Ahuja AT, et al. Quantitative elastography of liver fibrosis and spleen stiffness in chronic hepatitis B carriers: comparison of shear-wave elastography and transient elastography with liver biopsy correlation. Radiology. 2013;269(3):910-8.

27. Sporea I, Bota S, Gradinaru-Tascau O, Sirli R, Popescu A, Jurchis A. Which are the cut-off values of 2D-shear wave Elastography (2D-SWE) liver stiffness measurements predicting different stages of liver fibrosis, considering transient Elastography (TE) as the reference method? Eur J Radiol. 2014;83(3):e118-22.

28. Guibal A, Renosi G, Rode A, Scoazec JY, Guillaud O, Chardon L, Munteanu M, Dumortier J, Collin F, Lefort T. Shear wave elastography: An accurate technique to stage liver fibrosis in chronic liver diseases. Diagn Interv Imaging. 2016;97(1):91-9.

29. Zheng J, Guo H, Zeng J, Huang Z, Zheng B, Ren J, Xu E, Li K, Zheng R. Twodimensional shear-wave elastography and conventional US: the optimal evaluation of liver fibrosis and cirrhosis. Radiology. 2015;275(1):290-300.

30. Yegin EG, Yegin K, Karatay E, Kombak EF, Tuney D, Ataizi-Celikel C, Ozdogan OC. Quantitative assessment of liver fibrosis by digital image analysis: relationship to Ishak staging and elasticity by shear-wave elastography. J Dig Dis. 2015;16(4):217-27.

31. Zeng J, Liu GJ, Huang ZP, Zheng J, Wu T, Zheng RQ, Lu MD. Diagnostic accuracy of two-dimensional shear wave elastography for the non-invasive staging of hepatic fibrosis in chronic hepatitis B: a cohort study with internal validation. Eur Radiol. 2014;24(10):2572-81.

32. Beland MD, Brown SF, Machan JT, Taliano RJ, Promrat K, Cronan JJ. A pilot study estimating liver fibrosis with ultrasound shear-wave elastography: does the cause of liver disease or location of measurement affect performance? AJR Am J Roentgenol. 2014;203(3):W267-73.

33. Yoon JH, Lee JY, Woo HS, Yu MH, Lee ES, Joo I, Lee KB, Yi NJ, Lee YJ, Han $\mathrm{JK}$, et al. Shear wave elastography in the evaluation of rejection or recurrent hepatitis after liver transplantation. Eur Radiol. 2013;23(6):1729-37.

34. Bailey SS, Youssfi M, Patel M, Hu HH, Shaibi GQ, Towbin RB. Shear-wave ultrasound elastography of the liver in normal-weight and obese children. Acta Radiol. 2017;58(12):1511-8.

35. Ding $Y$, An Z, Wang S, Dou X. Efficacy evaluation of entecavir anti-fibrosis treatment in chronic hepatitis B with real-time shear wave elastography and ultrasound quantitative score. J Chin Clin Med Imaging. 2016;27(6):407-10.

36. Klauser AS, Miyamoto H, Bellmann-Weiler R, Feuchtner GM, Wick MC, Jaschke WR. Sonoelastography: musculoskeletal applications. Radiology. 2014,272(3):622-33.

37. Tsochatzis EA, Gurusamy KS, Ntaoula S, Cholongitas E, Davidson BR, Burroughs AK. Elastography for the diagnosis of severity of fibrosis in chronic liver disease: a meta-analysis of diagnostic accuracy. J Hepatol. 2011;54(4):650-9.

38. Sandrin L, Fourquet B, Hasquenoph JM, Yon S, Fournier C, Mal F, Christidis C, Ziol M, Poulet B, Kazemi F, et al. Transient elastography: a new noninvasive method for assessment of hepatic fibrosis. Ultrasound Med Biol. 2003;29(12):1705-13.

39. Liu Y, Liu J, Fite BZ, Foiret J, Ilovitsh A, Leach JK, Dumont E, Caskey CF, Ferrara $\mathrm{KW}$. Supersonic transient magnetic resonance elastography for quantitative assessment of tissue elasticity. Phys Med Biol. 2017;62(10):4083-106.

40. Junker D, De Zordo T, Quentin M, Ladurner M, Bektic J, Horniger W, Jaschke W, Aigner F. Real-time elastography of the prostate. Biomed Res Int. 2014,2014:180804.

41. Herek D, Herek O, Akbulut M, Ufuk F. Role of strain Elastography in the evaluation of testicular torsion: An experimental study. J Ultrasound Med. 2016;35(10):2149-58

42. Sim YT, Vinnicombe S, Whelehan P, Thomson K, Evans A. Value of shearwave elastography in the diagnosis of symptomatic invasive lobular breast cancer. Clin Radiol. 2015;70(6):604-9. 
43. Berg WA, Cosgrove DO, Dore CJ, Schafer FK, Svensson WE, Hooley RJ, Ohlinger R, Mendelson EB, Balu-Maestro C, Locatelli M, et al. Shear-wave elastography improves the specificity of breast US: the BE1 multinational study of 939 masses. Radiology. 2012;262(2):435-49.

44. Ferraioli G, Tinelli C, Malfitano A, Dal Bello B, Filice G, Filice C, Liver Fibrosis Study G, Above E, Barbarini G, Brunetti E, et al. Performance of real-time strain elastography, transient elastography, and aspartate-to-platelet ratio index in the assessment of fibrosis in chronic hepatitis C. AJR Am J Roentgenol. 2012;199(1):19-25.

45. Srinivasa Babu A, Wells ML, Teytelboym OM, Mackey JE, Miller FH, Yeh BM, Ehman RL, Venkatesh SK. Elastography in chronic liver disease: modalities, techniques, limitations, and future directions. Radiographics. 2016;36(7):1987-2006.

46. Ophir J, Alam SK, Garra BS, Kallel F, Konofagou EE, Krouskop T, Merritt CR, Righetti R, Souchon R, Srinivasan S, et al. Elastography: Imaging the elastic properties of soft tissues with ultrasound. J Med Ultrason (2001). 2002;29(4):155.

47. Hu X, Liu Y, Qian L. Diagnostic potential of real-time elastography (RTE) and shear wave elastography (SWE) to differentiate benign and malignant thyroid nodules: a systematic review and meta-analysis. Medicine (Baltimore). 2017;96(43):e8282.

48. Kennedy P, Wagner M, Castera L, Hong CW, Johnson CL, Sirlin CB, Taouli B. Quantitative Elastography methods in liver disease: current evidence and future directions. Radiology. 2018;286(3):738-63.

49. Bota S, Herkner H, Sporea I, Salzl P, Sirli R, Neghina AM, Peck-Radosavljevic M. Meta-analysis: ARFI elastography versus transient elastography for the evaluation of liver fibrosis. Liver Int. 2013;33(8):1138-47.

50. Kobayashi K, Nakao H, Nishiyama T, Lin Y, Kikuchi S, Kobayashi Y, Yamamoto T, Ishii N, Ohashi T, Satoh K, et al. Diagnostic accuracy of real-time tissue elastography for the staging of liver fibrosis: a meta-analysis. Eur Radiol. 2015;25(1):230-8

51. Elhosary YA, Saleh SM, Ezzat WM, Clevert DA. Diagnostic accuracy of acoustic radiation force impulse (ARFI) in diagnosis of liver fibrosis among Egyptian patients with chronic HCV infection. Open Access Maced J Med Sci. 2016;4(3):374-80

52. Kyriakidou G, Friedrich-Rust M, Bon D, Sircar I, Bogdanou S, Herrmann E, Bojunga J. Comparison of strain elastography, point shear wave elastography using acoustic radiation force impulse imaging and 2D-shear wave elastography for the differentiation of thyroid nodules. PLoS One. 2018;13(9):e0204095

53. Kato Y, Nakata K, Omagari K, Furukawa R, Kusumoto Y, Mori I, Tajima H, Tanioka $\mathrm{H}$, Yano M, Nagataki S. Risk of hepatocellular carcinoma in patients with cirrhosis in Japan. Analysis of infectious hepatitis viruses. Cancer. 1994;74(8):2234-8.

54. Lo RC, Kim H. Histopathological evaluation of liver fibrosis and cirrhosis regression. Clin Mol Hepatol. 2017;23(4):302-7.

55. Takano S, Yokosuka O, Imazeki F, Tagawa M, Omata M. Incidence of hepatocellular carcinoma in chronic hepatitis B and C: a prospective study of 251 patients. Hepatology. 1995;21(3):650-5.

56. Chin JL, Chan G, Ryan JD. Noninvasive assessment of liver fibrosis and cirrhosis with ultrasound-based Elastography in alcohol-related liver disease. Gastroenterology. 2016;150(5):1251-2.

57. Rizzo L, Calvaruso V, Cacopardo B, Alessi N, Attanasio M, Petta S, Fatuzzo F, Montineri A, Mazzola A, L'Abbate L, et al. Comparison of transient elastography and acoustic radiation force impulse for non-invasive staging of liver fibrosis in patients with chronic hepatitis C. Am J Gastroenterol. 2011;106(12):2112-20.

58. Bota S, Sporea I, Sirli R, Popescu A, Jurchis A. Factors which influence the accuracy of acoustic radiation force impulse (ARFI) elastography for the diagnosis of liver fibrosis in patients with chronic hepatitis C. Ultrasound Med Biol. 2013;39(3):407-12.

59. Deffieux T, Gennisson JL, Bousquet L, Corouge M, Cosconea S, Amroun D, Tripon S, Terris B, Mallet V, Sogni P, et al. Investigating liver stiffness and viscosity for fibrosis, steatosis and activity staging using shear wave elastography. J Hepatol. 2015;62(2):317-24.

60. Yoon JH, Lee JM, Woo HS, Yu MH, Joo I, Lee ES, Sohn JY, Lee KB, Han JK Choi Bl. Staging of hepatic fibrosis: comparison of magnetic resonance elastography and shear wave elastography in the same individuals. Korean J Radiol. 2013;14(2):202-12

\section{Publisher's Note}

Springer Nature remains neutral with regard to jurisdictional claims in published maps and institutional affiliations.

\section{Ready to submit your research? Choose BMC and benefit from}

- fast, convenient online submission

- thorough peer review by experienced researchers in your field

- rapid publication on acceptance

- support for research data, including large and complex data types

- gold Open Access which fosters wider collaboration and increased citations

- maximum visibility for your research: over $100 \mathrm{M}$ website views per year

At $\mathrm{BMC}$, research is always in progress.

Learn more biomedcentral.com/submissions 